\title{
Sarcoid related optochiasmatic arachnoiditis: favourable outcome confirmed with MRI
}
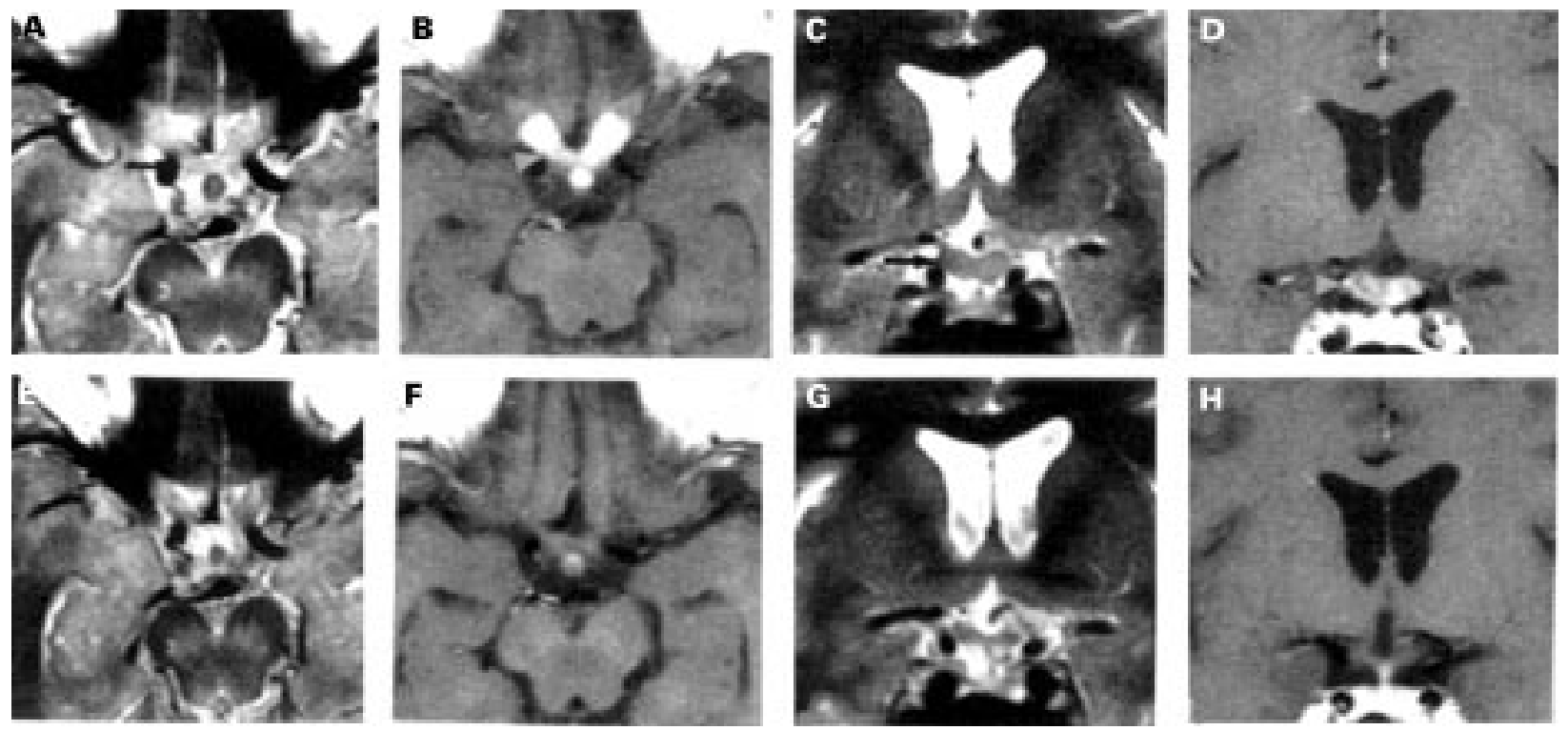

Cranial MRI (A-D) before treatment showed a hypertrophy of the optic chiasma and of the optic nerves, with hypersignal on T2 weighted images (A and $C$, black arrow) and ( $B$ and $D$, arrowhead) gadolinium enhancement on $T 1$ weighted images. Images ( $E-H)$ after corticosteroid treatment showed a decrease in the size and the intensity of the signal of both the optic chiasma and nerves ( $E$ and $G)$, with disappearance of gadolinium enhancement $(F$ and $H) . A, B, E$, and $F$ are in the axial plane; $C, D, G$, and $H$ are in the coronal plane; $A, E, C$, and $G$ are $T 2$ weighted images; $B, F, D$, and $H$ are postgadolinium, $T 1$ weighted images.

A 57 year old woman was admitted for bilateral visual loss, most marked on the right. Her medical history included longstanding pulmonary sarcoidosis (stage 1) with bilateral hilar adenopathy, which had been histologically established. No specific treatment had been given.

She presented with rapidly progressive visual loss over several days with pain on ocular movement and headache. The patient was asthenic, pale, and afebrile. The initial visual acuity was $1 / 6$ on the right eye and $3 / 6$ on the left eye. Ophthalmic examination showed bilateral pallor of the papillae but no uveitis. The rest of the clinical examination, including the respiratory and neurological systems, was unremarkable. Laboratory examination disclosed an inflammatory syndrome with an erythrocyte sedimentation rate of $45 \mathrm{~mm}$ in the first hour. Examination of the CSF showed an aseptic meningitis with an increased protein concentration (81 cells $/ \mathrm{mm}^{3}$ (99\% lymphocytes), protein $1.15 \mathrm{~g} / 1$ without intrathecal IgG synthesis). The blood concentration of angiotensin converting enzyme was increased $(0.36 \mathrm{nmol} /$ $\mathrm{min} / \mathrm{ml}$ (normal 0.06-0.20)). A radiograph of the chest and an EMG showed no abnormalities.

Cranial MRI (figure, top panels) showed hypertrophy of the chiasma and of the cisternal portion of both optic nerves, a hypersignal on T2 weighted images (A and C), and post-gadolinium enhancement on $\mathrm{T} 1$ weighted images (B and D) was present.

The patient was treated with high doses of steroids - an infusion of $1 \mathrm{~g} /$ day methylprednisolone for 3 days, followed by $1 \mathrm{mg} / \mathrm{kg} /$ day oral prednisone for 1 month. Her overall condition improved. Ocular pain resolved rapidly over 2-3 days and visual acuity returned to normal (visual acuity
$=5 / 6$ on both sides) within 4 weeks. The laboratory indices of inflammation and the CSF returned to normal within 6 weeks.

A control MRI (E, F, G, and $\mathrm{H}$ ) was performed 2 months after the onset of treatment: a decrease in the size of both the chiasma and optic nerves, as well as the hypersignal on T2 weighted images ( $E$ and $G$ ), was seen. The post-gadolinium enhancement on $\mathrm{T} 1$ weighted images disappeared ( $\mathrm{F}$ and $\mathrm{H})$.

Steroid treatment is effective in optochiasmatic arachnoiditis due to sarcoidosis ${ }^{1-3}$ and the response to treatment can be easily monitored clinically and with cranial MRI. ${ }^{4}$

HASSAN HOSSEINI AYMAN TOURBAH

Fédération de Neurologie, Hôpital de la Salpêtrière, 47 Boulevard de l'Hôpital, 75651 Paris Cedex 13, France

HASSAN HOSSEINI

Département de Neurosciences, INSERM U421, 8 rue du Général Sarrail, 94010 Créteil Cedex, France

AYMAN TOURBAH

Service de Neuroradiologie, CHNO des XV-XX, 28 rue de Charenton 75012 Paris, France

Correspondence to: Dr Ayman Tourbah, Fédération de Neurologie, Hôpital de la Salpêtrière, 47 Boulevard de l'Hôpital, 75651 Paris Cedex 13, France. Telephone 00331 42161762; fax 0033142161965.

Newman LS, Rose CS, Maier LA. Sarcoidosis. $N$ Engl $f \mathrm{Med}$ 1997;336:1224-34.

2 Scott TF. Neurosarcoidosis: progress and clinical aspects. Neurology 1993;43:8-12.

3 Agbogu BN, Stern BJ, Sewell C, et al . Therapeutic considerations in patients with refractory neurosarcoidosis. Arch Neurol 1995;52:875-9.

4 Beck AD, Newman NJ, Grossniklaus HE, et al. Optic nerve enlargement and chronic visual loss. Surv Ophthalmol 1994;38:555-66. 